\title{
CORROSION INFLUENCE ON SAFETY OF HYDRAULIC PIPELINES INSTALLED ON DECKS OF CONTEMPORARY PRODUCT AND CHEMICAL TANKERS
}

\author{
Andrzej Banaszek ${ }^{1}$ \\ Zbigniew Losiewicz ${ }^{1}$ \\ Wojciech Jurczak ${ }^{2}$ \\ ${ }^{1}$ West Pomeranian University of Technology, Faculty of Maritime Technology and Transport, Poland \\ ${ }^{2}$ Naval Academy, Mechanical-Electric Faculty, Poland
}

\begin{abstract}
The corrosion influence on hydraulic pipelines safety mounted on product and chemical tankers has been presented in this paper. The issue of axial forces in pipelines mounted along ship open decks, resulting from ship hull deformations in waves, is highlighted. Corrosion degradation phenomena of hydraulic pipelines on open deck is described. The analysis of degradation effect on thickness of carbon steel material of pipes is given and influence of the effect on stress level increase in hydraulic pipelines during exploitation at sea is focused. The discussion about fighting against corrosion in hydraulic pipelines on open decks is performed. All the problems analyzed in the paper are based on examples of events observed on product and chemical tankers built in Szczecinska Shipyard, Szczecin, Poland.
\end{abstract}

Keywords: Keywords: corrosion, safety, hydraulic pipelines, Huber-Mises stresses, product and chemical tanker

\section{INTRODUCTION}

Corrosion is an important issue for all ships sailing worldwide. It especially concerns product and chemical tankers, i.e. ships intended for the transporting of liquid oil products and chemical cargoes by sea. As a rule they constitute dangerous liquid cargoes of explosive as well as toxic nature and hazardous regarding their agressive chemical effects onto metals and people. Cargo space of the contemporary product and chemical tankers is subdivided into many various separate cargo tanks $[1,3,4,5,6,7]$. As a result, it allows to carry, during one sea voyage, many different liquid cargoes in relatively small amounts as far as sea transport has been concerned. Such structural arrangement of the ships allows to utilize their cargo space better because in port terminals there are usually many various liquid cargoes to be transported by sea, but in relatively small amounts. For this reason on decks of the contemporary product and chemical tankers many various pipeline systems intended for the handling of transported liquid cargoes, are installed [1-7]. In view of chemical reactivity of a cargo or its possible contamination there are very often installed in every tank seperate immersed hydraulic pumps for its direct servicing $[1,2]$. For this reason central hydraulic power supply systems intended for the driving and controlling of the immersed hydraulic cargo pumps belong to the crucial shipboard installations $[1,2,3,4]$.

The mentioned hydraulic drive systems belong to the largest hydraulic systems in the whole maritime technology due to amount of power installed in their supply units. For instance, on the B573-I/1 product tanker "Engen Rainbow” the total power of the hydraulic supply unit amounted to abt. $1800 \mathrm{~kW}$ [4].

The conditions in which hydraulic installations are used at sea are numbered among especially difficult. On the one hand, the pipes installed on board of sea-going ships are loaded by high internal pressure of hydraulic oil (up to $30 \mathrm{MPa}$ [3]), on the other hand, an additional load resulting from ship hull deformations in sea waves is applied from outside together with ambient temperature changes. 
For the reason that stresses are changeable the corrosion damage phenomenon may affect hydraulic piping safety and reliability of the whole central hydraulic power supply system. Its impact is presented in this paper.

\section{ISSUE OF CORROSION IN SHIPBOARD PRESSURE PIPING INSTALLATIONS AND CORROSION TYPES}

Corrosion damage is considered a serious problem in ocean engineering and one of the most frequent causes of ship structural failures. It concerns also pipe constructions, including hydraulic piping installations. According to the investigations of World Corrosion Organization (WCO) it is estimated that as a result of corrosion about 3\% of Gross Domestic Product (GDP) is lost worldwide, that amounts to abt. 2,4 billion USD per year [11]. In case of US the cost reaches $4 \%$ GDP and has tendency to increase.

Pressure piping installations, including hydraulic ones suffer failures under corrosion action in two modes:

- by fractures when allowable stresses are exceeded in pipe material,

- by loss of tightness of pipe joints resulting from corrosion action and corrosion process products.

In 1998 a hydraulic pipe, a part of pressure pulsation damper in the $2200 \mathrm{~kW}$ hydraulic supply unit (Power Pack) was cracked on the product tanker "Helix"built in Szczecin Shipyard Porta Holding SA [6,7]. The crack of the pipe resulted in dangerous fire in the Power Pack Room located in the ship power plant and consequently caused withdrawal of the tanker from service for 2 months.

As far as other pressure installations are concerned the following events may be numbered among the most known: - a large gas condensate spill resulting consequently in dangerous fire on the platform "Piper Alpha " in 1988, [11]. The accident was caused by pitting corrosion and resulted in the death toll of 167 persons - being the largest one in history of gas and oil industry.

- similar accident happened in September 2012, where 125 barrels of oil and $1600 \mathrm{~kg}$ of gas leaked from the Norwegian platform "BP ULA" to the North Sea [9].

- in December 2012 a gas pipline under operation of Columbia Gas Transmission Inc. exploded [13]. Also in this case the accident resulted from pitting corrosion of the pipeline. Though there was no loss of human life, $2 \mathrm{mln} \mathrm{m}^{3}$ of natural gas was burnt and financial loss for the enterprise amounted to $9 \mathrm{mln}$ USD.

The above described catastrophies resulted in an increase of interest from the side of scientists in research on corrosion phenomena in offshore pipelines [9-16]. Unfortunately, in the worldwide subject-matter literature there is a lack of research publications concerning high-pressure hydraulic installations mounted on board of offshore objects, including product and chemical tankers.

Corrosion is defined to be destruction of a material, especially metal or metal alloys, resulting from its reaction with surrounding environment. The environment may affect in various ways - by temperature ( winter - summer), radiation (e.g. UV part of solar radiation), chemical impact of water ( especially salt or contaminated sea water ), cavitation due to flowing liquids etc. An important element of carbon steel corrosion process in sea environment is also oxygen depolarization phenomenon. Without oxygen presence the described corrosion process is not possible to develop.

As results from the above presented set of accidents associated with loss of tightness of pipelines, the intensive local corrosion leads to the most catastrophic effects. It occurs in the form of local, deep and locally spread damages of steel, which result from anodic reaction in the damage bottom and cathodic reaction occurring in the surrounding of spot of the corrosion. The local corrosion may lead to loss of tightness in installation pipelines accommpanied with a leakage of a medium flowing through the installation. It is important for the hydraulic installations where inside the pipes high pressure of oil takes place up to $30 \mathrm{MPa}$ [1].

\section{PROBLEM OF STRESS GENERATION IN HYDRAULIC PIPELINES MOUNTED ALONG SHIPS OPEN DECK}

\section{ELONGATIONS IN HYDRAULIC INSTALLATIONS RESULTING FROM DEFORMABILITY OF SHIP HULL ON SEA WAVE}

Pipelines mounted on ship deck are affected by changeable tension - compression load resulting from ship hull deformability on sea wave. On the crest of long sea wave the ship undergoes hogging deformation. (see Fig.1a). In the opposite situation where the midship is in the wave hollow it undergoes sagging deformation (sea Fig.1b)
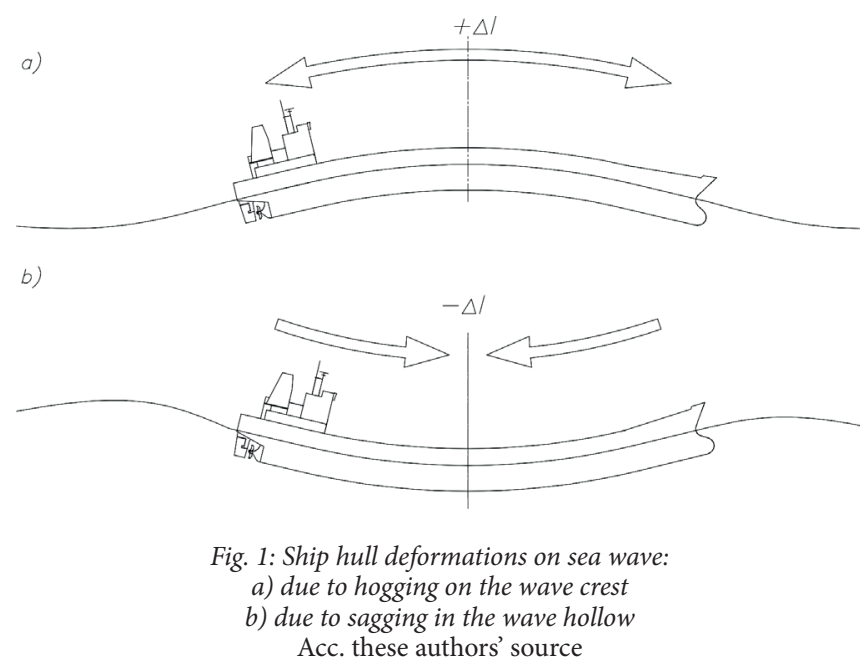

Magnitude of the deformations depends on many factors such as distribution of ship's own weight, state of loading and ballasting, kind of hull structure and form of sea wave. There 
is a lack of publications concerning the issue in the subjectmatter literature. For this reason the necessity of ensuring appropriate compensation on ship deck is sometimes neglected, that results in serious failures. It may be exemplified by cracks in cargo valve feeding pipes on B560 product tankers built in Stocznia Szczecinska in the last years of the 1980s. During sea service of the ships a rupture in hydrostatic installation pipelines mounted along ship deck occurred as a result of a too small number of elongation compensators. In consequence, serious failures in hydraulic control system occurred as well as a pollution of sea environment resulting from hydraulic oil leakage took place.

According to [23] it may be approximately assumed that if in the deck or bottom of the ship hull Huber-Mises stress values of about $140 \mathrm{MPa}$ occur (at Young modulus value $E=2,1 \cdot 10^{5}[\mathrm{MPa}]$ for a steel of which the hull was built), then the ratio between hull bending deflection and ship length amounts to about 1:1500. Basing on this statement one can assume that a ship of $L_{c}=183 \mathrm{~m}$ in length shows the hull bending deflection $f_{c}=0,122 \mathrm{~m}$. It is rather not an easy task to determine on this basis how large is elongation/ compression of ship's open deck as such value depends on ship hull structure. Assuming the analogue value of average stresses in ship hull equal to $140 \mathrm{MPa}$, one is able to calculate, by using Hook's law, the above mentioned value of elongation/ compression of ship deck/bottom equal to $0,12 \mathrm{~m}$. Therefore it can be assumed that the deck elongation is approximately close to the value of the hull bending deflection. To determine in detail the value in question it is necessary to perform a numerical analysis of ship hull structure by means of the finite element method ( FEM), for instance, such as the calculation of hull deformations of the B573-I/1 product tanker „Engen Rainbow”, performed by shipyard's design office [19]. On this basis it was determined that the hull of the product tanker in question in hogging state may reach elongation equal to $\Delta l_{c}=0,11 \mathrm{~m}$.

\section{ELONGATION OF HYDRAULIC ISTALLATIONS RESULTING FROM THERMAL DEFORMATIONS}

Not only deformations of ship hull on wave affect values of stresses and deformations generated in pipelines mounted on ship decks. The other important issue is thermal expansion phenomenon of materials used for the pipes. It is assumed that change in pipe length is proportional to change in pipe material temperature[17].

$$
l=l_{0} \cdot\left(1+\alpha_{L} \cdot \Delta t_{K}\right)
$$

gdzie:

$l$ - pipe length after rise of pipe material temperature,

$l_{0} \quad$ - initial pipe length,

$\Delta t_{K}$ - temperature rise in pipe mateial,

$\alpha_{L}$ - thermal linear expansion coefficient of pipe material (it shows how much unit length of material is enlarged after heating it by $1{ }^{\circ} \mathrm{C}$.
In the literature [17] for initial analyses are given nomograms from which changes in length of hydraulic pipes can be found in function of their intitial length and temperature change (see Fig. 2).

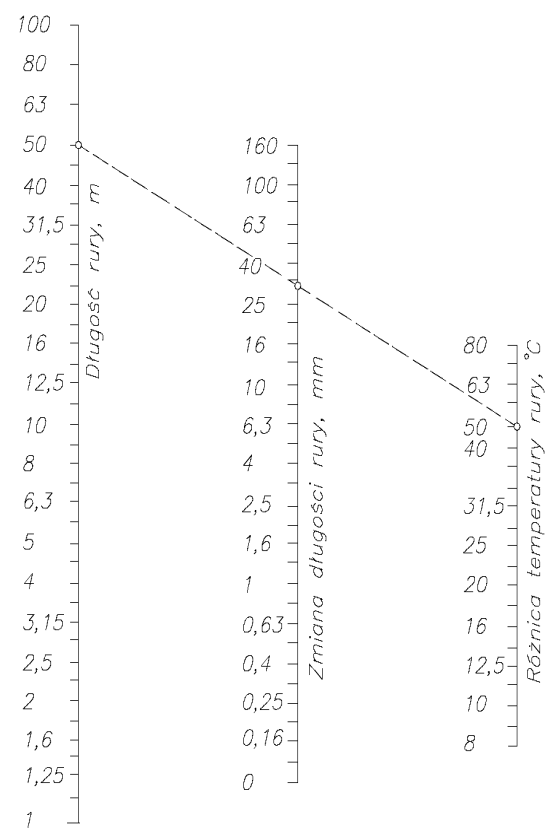

Fig. 2. Nomogram for determining values of changes in carbon steel pipes resulting from changes in their temperature

Source: these authorsown work based on Mannesmann Rexroth, Vademecum of hydraulics, Vol. 3 [17]

Tab. 1. Recommended dimensions of U -pipe compensators for hydraulic pipes used on ships built in Stocznia Szczecinska S.A.

Source: these authorsown work based on the shipyard's materials [19]

\begin{tabular}{|c|c|c|c|c|c|c|}
\hline \multicolumn{7}{|c|}{ E } \\
\hline 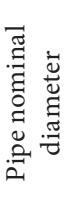 & 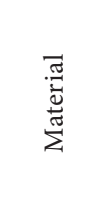 & 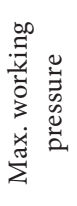 & 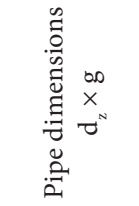 & 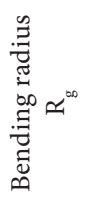 & 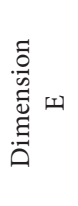 & 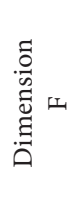 \\
\hline $\mathrm{mm}$ & - & $\mathrm{MPa}$ & $\mathrm{mm}$ & $\mathrm{mm}$ & $\mathrm{mm}$ & $\mathrm{mm}$ \\
\hline 50 & E355+N & 32.0 & $65.0 \times 7.0$ & 195 & 800 & 800 \\
\hline 60 & $\mathrm{E} 355+\mathrm{N}$ & 32.0 & $80.0 \times 10.0$ & 230 & 1500 & 900 \\
\hline 70 & E355+N & 32.0 & $90.0 \times 10.0$ & 230 & 1500 & 1200 \\
\hline 80 & $\mathrm{E} 355+\mathrm{N}$ & 32.0 & $100.0 \times 10.0$ & 250 & 1500 & 1400 \\
\hline 90 & $\mathrm{E} 355+\mathrm{N}$ & 32.0 & $110.0 \times 11.0$ & 275 & 1500 & 1400 \\
\hline 100 & $\mathrm{E} 355+\mathrm{N}$ & 32.0 & $120.0 \times 12.0$ & 300 & 1500 & 1400 \\
\hline 110 & $\mathrm{E} 355+\mathrm{N}$ & 32.0 & $130.0 \times 13.0$ & 325 & 1500 & 1400 \\
\hline
\end{tabular}

As may be observed from the attached nomogram for carbon steel pipes, the steel pipe segment of $50 \mathrm{~m}$ in length will be longer by $0,04 \mathrm{~m}$ due to temperature change by $50^{\circ} \mathrm{C}$. In line with Hook's law the mentioned temperature change can lead to generating, in a straight pipe fixed at both ends 
and without compensation, axial stress equal to $168 \mathrm{MPa}$ (without taking into account hydraulic oil pressure and ship hull deformations). Worth remembering, that many seagoing ships are of unrestricted range of operation - from equatorial waters up to the Arctic Sea. Starting the hydrostatic drive system in such conditions may lead to significant changes in temperature of pipe installation. The nominal service temperature of hydraulic oil recommended by many producers of displacement pumps should be equal to $50{ }^{\circ} \mathrm{C}$. On the other hand, in line with the technical descriptions of product and chemical tankers built in Stocznia Szczecinska [19] the ships should so designed as to be capable of operating in ambient (air) temperature in the range from $-20^{\circ} \mathrm{C}$ (winter) up to $+35^{\circ} \mathrm{C}$ (summer) as well as at water temperature from $0{ }^{\circ} \mathrm{C}$ (winter) up to $+35^{\circ} \mathrm{C}$ (summer). Worth mentioning, that in summer tropical waters temperature of open deck plating can be even higher due to solar radiation action.

\section{EXAMPLE NUMERICAL ANALYSIS}

Hydraulic pipe installation mounted on ship deck must be firmly fixed to hull structure with every definite step of length. The fixing place called also the anchoring point of installation is localized as a rule close to a compensator. It results from that in case of occurrence of axial forces in the installation the anchoring point makes the transferring of the occurring deformations by means of the compensator, possible. In case of a longer installation the application of a number of anchoring points prevents a single compensator against concentration of all the axial forces just on it and allows to distribute the forces proportionally into all the remaining compensators mounted along the whole pipeline.

Tab.2. Strength properties of E355 $+N$ carbon steel

Source: Mannesmann Rexroth, Vademecum of hydraulics, Vol. 3 [17]

\begin{tabular}{|c|c|c|c|c|c|}
\hline 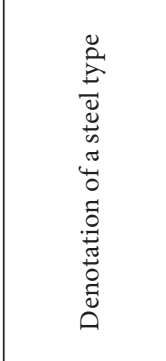 & 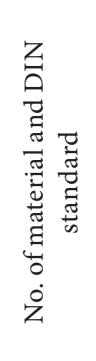 & 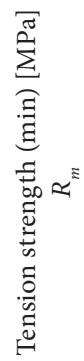 & 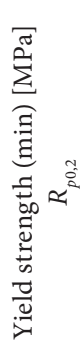 & 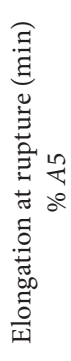 & 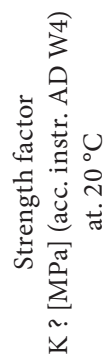 \\
\hline $\begin{array}{c}\text { Carbon steel } \\
\text { E355+N }\end{array}$ & $\begin{array}{c}1.0581 \\
1630\end{array}$ & 490 & 350 & 21 & 355 \\
\hline
\end{tabular}

In the analysis with the use of the finite element method (FEM) there was assumed that the right end of the compesator was fixed in pivot support [18], and its other end was left free. The basic deformation of the compensator, $\mathrm{dx}[\mathrm{mm}]$, was applied to its left end. The analysis of deformations and generated forces in the fixed support of the compensator was carried out numerically by using FEM method. The calculations were conducted by means of the computer software ABAQUS Ver.6.7 [18] with the use of the shell finite element FEM 3D S4R. It is a spatial element of 9 nodes and 45 degrees of freedom, well adjusted to modelling shell structures, including pipes of any type and installations. In Tab. 3 there are given example results of calculations of maximum Huber-Mises stresses occurring in the compensator under action of compression deformations with and without taking into account hydraulic oil pressure. The obtained relations are presented in Fig.4.

The analyzed relation between maximum value ofgenerated Huber-Mises stresses and value of $\mathrm{dx}$ - deformation is of a linear character and the stresses strongly depend on values of internal oil pressure in pipe. Therefore, in contrast to anchoring forces, the omitting of oil pressure in the stress analysis leads to occurrence of large errors and is impermissible even in case of simplified calculations.

Tab.3. Results of FEM calculations of maximum values of Huber-Mises stresses in compensator under action of compression deformation by $d x$. Source: these authors'own calculations by using the software ABAQUS Ver. 6.7

\begin{tabular}{|c|c|c|c|}
\hline 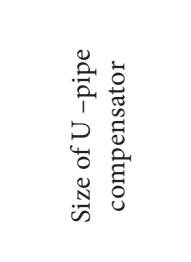 & $\ddot{\theta}$ & 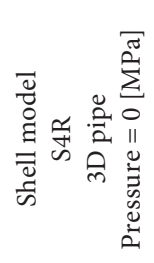 & 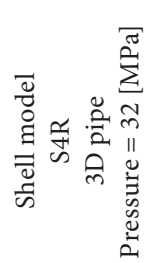 \\
\hline \multirow{7}{*}{$\begin{array}{c}\phi 130 \times 13 \mathrm{~mm} \\
\mathrm{~L}=2550 \mathrm{~mm} \\
R_{g}=325 \mathrm{~mm}\end{array}$} & $\mathrm{~mm}$ & $\mathrm{MPa}$ & $\mathrm{MPa}$ \\
\hline & 5 & 39,7 & 179,0 \\
\hline & 10 & 79,5 & 213,7 \\
\hline & 15 & 119,3 & 246,5 \\
\hline & 20 & 159,1 & 284,7 \\
\hline & 25 & 198,8 & 321,4 \\
\hline & 30 & 238,6 & 358,5 \\
\hline
\end{tabular}

The linear character of the relation of maximum values of Huber-Mises stresses in function of $\mathrm{dx}$ - deformation is a great advantage of the elongation compensators in question. This may explain why the analyzed compensators are so often used in shipbuilding and other industrial branches. The results of calculations well coincide with results of laboratory measurements made in Framo workshop, Norway [19], especially in case of taking into account the model with internal pressure in pipe.

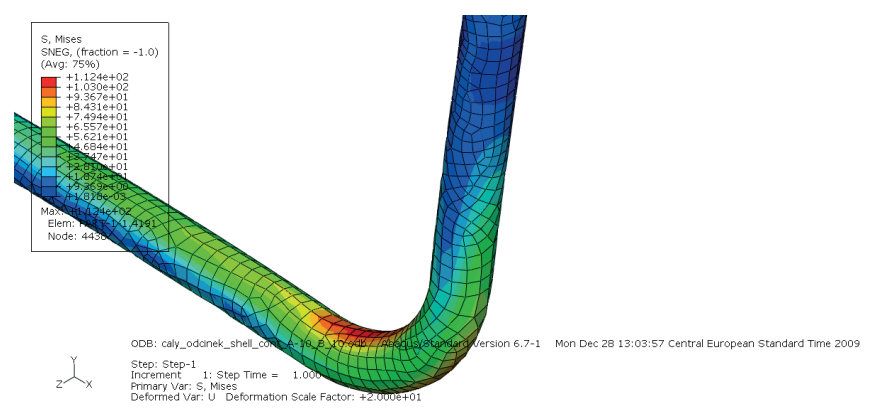

Fig.3. Image of example concentrations of Huber-Mises stresses in the analyzed elongation compensator of $\phi 130 \times 13 \mathrm{~mm}$ under action of compression deformations

Source: these authorsown work by using the software ABAQUS Ver. 6.7 
Denotation of calculation results:

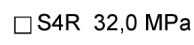

Pipe $130 \times 13 \mathrm{~mm}$

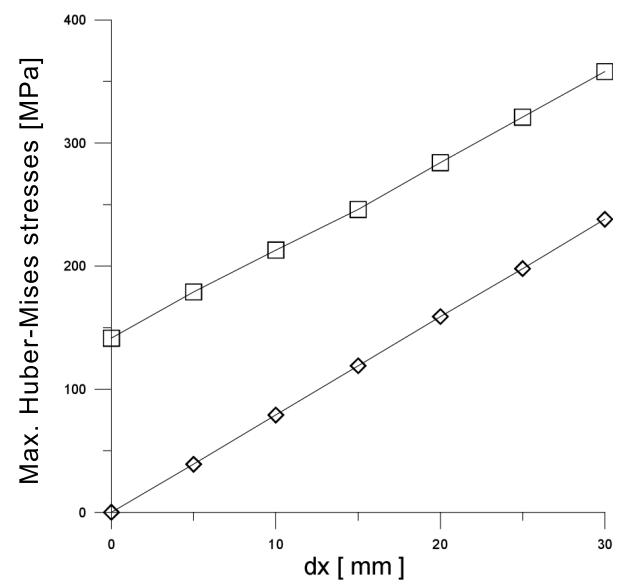

Fig.4. Relation of maximum values of Huber-Mises stresses in the analyzed $U$ - pipe compensator of $\phi 130 \times 13 \mathrm{~mm}$ under action of $d x$ - compression defomation Source: these authors' own work

In Fig. 3 there are presented example concentrations of Huber-Mises stresses in the analyzed pipe elongation compensator of $\phi 130 \times 13 \mathrm{~mm}$ under action of compression deformations. The maximum values of Huber-Mises stresses in the analyzed compensators were located in bent piping segments inside the compensator structure (see Fig. 3).

\section{ASSESSMENT OF CORROSION INFLUENCE ON VALUE OF HUBER-MISES STRESSES IN CENTRAL POWER SUPPLY HYDRAULIC PIPE INSTALLATIONS}

According to Lloyds Register [21] the minimum thickness of pressure duct, including hydraulic ones, should be equal to:

$$
t=\left(\left(\frac{p \cdot D}{20 \cdot \sigma \cdot e+p}\right) \cdot\left(1+\frac{D}{2,5 \cdot R}\right)+c\right) \cdot\left(\frac{100}{100-a}\right)
$$

where

$\sigma=\frac{R_{20}}{2,7}[\mathrm{~N} / \mathrm{mm}]-$ maximum allowable design stress in

$R_{20}$ - yield strength in ambient temperature, $[\mathrm{N} / \mathrm{mm}]$,

D - outer pipe diameter $[\mathrm{mm}]$,

$\mathrm{R}$ - pipe bending radius [mm],

a - odd percentage working tolerance for pipe wall thickness,

e - factor of workmanship class of weld; for seamless pipes (without seam) $\mathrm{e}=1$, c - corrosion allowance; for hydraulic pipes $\mathrm{c}=0,3 \mathrm{~mm}$,

p - allowable pressure [bar].

Fast corrosion deals especially with curved segments of the described U-pipe compensators where stress concentration occurs during service. In the places paint cover suffers early failures and subsequent corrosion which is of a local pitting character, quasi-uniformly spread around the pipe. Therefore in the analysis of corrosion influence on value of generated Huber-Mises stresses there was assumed the simplified model of uniform corrosion to be most detrimental for transverse cross-section of pipe and most unfavourably affecting the generated Huber_Mises stresses in points of their concentration in curved segments of the $\mathrm{U}$ - pipe compensators in question.

Worth mentioning, that in the strength analysis of the hydraulic pipe under action of local corrosion the assumed thin-wall condition in the form of $\frac{t}{r}<0,2$ was fulfilled.

For the estimating of fastness of corrosion process influence on the hydraulic pipe compensator in question, there was not possible to make use of the notion of pipe mass loss resulting from corrosion action, according to the assumptions given by Banaś and W. Solarski [22]. Hence, based on these authors experience, it was decided to apply the notion of the unit percentage corrosion fastnes $v_{f}$ [22]. The unit percentage corrosion fastness expresses speed of losing a selected definite property of an analyzed pipe due to corrosion per a given time unit ( a year):

$$
v_{f}=\frac{W_{o}-W}{W_{o} \cdot t c z} \cdot 100 \%
$$

where

$W_{o}$ - a selected physical property of pipe material at the beginning of corrosion process

$W$ - a selected physical property of pipe material at the end of corrosion process,

tcz - time [year]

In the considered case there was assumed that analyzed physical properties of compensator material are the following: $W_{o}$ - the maximum Huber-Mises stresse $\sigma$, generated by tension forces (resulting in the deformation $\mathrm{dx}=30 \mathrm{~mm}$ ) together with oil nominal pressure acting onto hydraulic elongation compensator, calculated with the use of the above presented FEM analysis for the beginning of the corrosion process, i.e. for the assumed nominal thickness of the analyzed compensator pipe (of the dimensions given in Tab. 3)

$W$ - Huber-Mises stresses in the elongation compensator, calculated for the same conditions as the above given, but for the thickness of the compensator pipe walls decreased by $\Delta t$.

Therefore, as in such case the corrosion process leads to diminishing the live cross-section area of the analyzed pipe and consequently to increasing Huber-Mises stresses at the 
same conditions of action of external and internal loads, the resulting values of the unit percentage corrosion fastnes $v_{f}$ become negative.

Tab.4. Calculation results of the unit percentage corrosion fastness $v_{f}$ in function of the local corrosion damage depth $\Delta t$ in the elongation compensator pipe of $\phi 130 \times 13 \mathrm{~mm}$

\begin{tabular}{|l|c|c|c|}
\hline $\begin{array}{l}\text { Dimensions of U-pipe } \\
\text { compensator }\end{array}$ & $\mathrm{p}$ & $\Delta t$ & $v_{f}$ \\
\hline \multirow{3}{*}{$\begin{array}{l}\text { Pipe } \\
\phi \mathrm{D} z \times \mathrm{t}= \\
\phi 130 \times 13 \mathrm{~mm} \\
\mathrm{~L}=2550 \mathrm{~mm} \\
\mathrm{R}_{\mathrm{g}}=325 \mathrm{~mm}\end{array}$} & 32 & $\mathrm{~mm}$ & $\%$ \\
\cline { 2 - 4 } & 32 & 1.0 & $-4,000$ \\
\cline { 2 - 4 } & 32 & 1.5 & $-13,043$ \\
\cline { 2 - 4 } & 32 & 2.0 & $-18,182$ \\
\cline { 2 - 4 } & 25 & 2.5 & $-23,810$ \\
\hline
\end{tabular}

The results presented in Tab. 4 and Fig. 5 show how much the local corrosion of the circumferentially uniform form is dangerous for hydraulic pressure piping in central power supply systems installed on board contemporary product and chemical tankers, especially for their elongation compensators. Corrosion damages of $\Delta t=2.5 \mathrm{~mm}$ in depth result in $23,8 \%$ loss of strength, that may lead to destruction of the analyzed hydraulic pipe. The phenomenon is so much dangerous as many shipboard mechanisms crucial for ship's safety, e.g. anchoring-mooring winches, are fed from a central power supply system, [5,6,7].

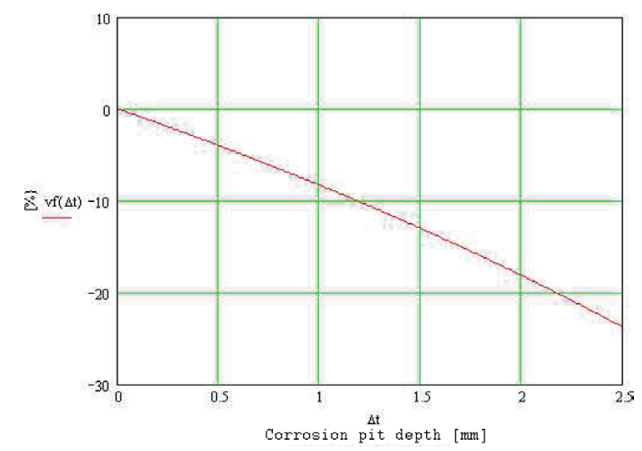

Fig. 5. The relation of the unit pecentage corrosion fastness $v_{f}$ in function of the corrosion pit depth $\Delta t$ in the pipe elongation compensator of $\phi 130 \times 13 \mathrm{~mm}$.

Source: these authors'own work

Loss of tightness of a hydraulic installation leads also to a lack of possiblity to unload a given product or chemical tanker causing in consequence large financial losses for its shipowner. As the pipeline in question is mounted on open deck, any leakage of hydraulic oil may cause pollution to the natural environment. To avoid such problems it is necessary to pay attention to providing good anti-corrosion prevention means for hydraulic installations mounted on open decks of the ships, especially for their pipe elongation compensators.

\section{SUMMARY}

Long hydraulic pipes, especially these connected with central power supply system for hydraulic pumps, mounted along open deck of contemporary product and chemical tankers, are susceptible to loads resulting from periodically varying ship hull deformations in waves, thermal expansion resulting from hydraulic oil temperature changes and solar radiation rate. To prevent the piplines against rupture, U-shape elongation compensators are used. In their curved segments maximum values of Huber-Mises stresses are concentrated.

The issue of corrosion in hydraulic piping significantly influences safety of the installation, entire ship as well as ecological safety of natural environment against polution. The most dangerous corrosion form which detrimentally affects hydraulic piping strength is pitting corrosion.

In case of the analyzed elongation compensators, value of unit percentage corrosion fastness increases along with growing corrosion pit depth. Hence, there is recommended to pay special attention to applying effective anti-corrosive protection means to hydraulic piping, especially the curved segments of elongation compensators where maximum values of Huber-Mises stresses are cummulated during ship service and the biggest danger of loss of hydraulic installation tightness exists.

\section{BIBLIOGRAPHY}

1. A.Banaszek:The selected elements of designing and operation of hydraulic central power supply systems on modern product and chemical tankers (in Polish). West Pomeranian University of Technology Press, Szczecin 2013, pp. 259,

2. A.Banaszek, R.Petrovic:FEM analysis of pipe material temperature changes influence on line expansion loops in hydraulic installation mounted on modern product and chemical tankers. Thermal Science (Vinci) No. 4/2013

3. A.Banaszek: The concept of central hydraulic loading system on board product and chemical tankers. First International Conference „Ship machines and equipment operation”, Świnoujście-Ystad-Copenhagen 2003, Zeszyty Naukowe Wyższej Szkoły Morskiej No. 68, Szczecin 2003

4. A.Banaszek: Liquid cargo installation systems analysis on product and chemical tankers (in Polish). Report of Baltecologicalship Research Project KBN Eureka 4-0000432/14-01-00/Contract No. 1518/2002,, Szczecin 2002

5. A.Banaszek: The concept of capacity control of submerged cargo pumps in liquid cargoes transport at sea. Marine Technology Transactions, Vol.16, Polish Academy of Sciences, Branch in Gdansk, 2005

6. A.Banaszek: Big power central hydraulic loading systems on board product and chemical tankers. The $19^{\text {th }}$ International 
Conference on Hydraulics nad Pneumatics, Prague, Czech Republic, 30-31 May 2006

7. A.Banaszek: Central hydraulic loading systems used on board product and chemical tankers (in Polish). Hydraulika i Pneumatyka No. 4/2003

8. Herbert H., Uhlig E.: The corrosion handbook, John Wiley and Sons Inc. New York 1969

9. Sandwith C.J., Clark R.C. Marine Corrosion of Selected Small Wire Ropes and Strains, Journal IEEE Ocean ' 75 pp. 148-154

10. Bhandari J., Faisal Khan b, Rouzbeh Abbassi a, Vikram Garaniya a, Roberto Ojeda: Modelling of pitting corrosion in marine and offshore steel structures - a technical review. Journal of Loss Prevention in the Process Industries 37 (2015) pp.39-62

11. Maureen et al.: Corrosion related Accidents in Rafineries: Lessons Learned from Accidents in EU and OECD Countries. Publications Office in EU, 2013

12. Melchers R.: Corrosion Wastage in Aged Structures. Condition Assessment of Aged Structures, 2008

13. Velazquez et al.: Statistical modeling of pitting corrosion: extrapolation of the maximum pit depth growth. International Journal of Electrochemical Science, 9 (2014) pp.4129-4143

14. Board N.T.S.; Columbia Gas Transmission Corporation Pipeline Rupture, Raport 2014

15. Poopola et al.: Corrosion problems during oil and gas production and its mitigation. International Journal of India Chemicals 4 (2013) pp.35

16. Nesic S.: Key issues related to modelling of internal corrosion of oil and gas pipelines - a review, Corrosion Science, 49 (2007) pp.4308-4338

17. Mannesmann Rexroth $\mathrm{GmbH}$, Vademecum of hydraulics. Volume 3, Design and structure of hydraulic systems (in Polish). Mannesmann Rexroth Verlag (Polish edition), RPL 00281/10.88, Lohr a. Main, Germany 1992

18. Hobbit, Karlsson, Soersen Inc.: ABAQUS ver.6.7 User's manual, Pawtucket, USA 2006

19. Stocznia Szczecinska SA: Technical documentation of B578I/542-1 (Shipyard internal materials) (in Polish), Szczecin 1997

20. Kucheryavyi V. I., Mil'kov S. N.: Probabilistic prediction of the residual lifetime of a gas pipeline under pitting corrosion. Journal of Machinery Manufacture and Reliability 2011, vol. 40, No. 5, pp. 489-493.

21. Lloyds Register: Rules and Regulations for the Classification of Ships, Part 5, Chapter 12, Section 2, London 2012.

22. A joint publication, Banaś J. And Solarski W. Editors: Chemistry for engineers (in Polish), AGH OEN, Kraków 2000

23. Orszulok W.: Ship's hull strength in exploitation (in Polish) Wyd. Morskie, Gdansk 1983.

\section{CONTACT WITH THE AUTHORS}

\author{
Wojciech Jurczak \\ e-mail:w.jurczak@amw.gdynia.pl \\ Naval Academy \\ Mechanical-Electric Faculty, \\ Śmidowicza 69 \\ 81-127 Gdynia \\ POLAND \\ Andrzej Banaszek \\ e-mail: andrzej.banaszek@zut.edu.pl
}

West Pomeranian University of Technology

Faculty of Maritime Technology and Transport

Al. Piastów 41

71-065 Szczecin

Poland

\section{Zbigniew Łosiewicz \\ e-mail:zbigniew.losiewicz@zut.edu.pl}

West Pomeranian University of Technology Faculty of Maritime Technology and Transport Al. Piastów 41

71-065 Szczecin

Poland 